NBSIR 78-1452

\title{
An Evaluation of Children's Biting Strength for Toy Safety Criteria
}

Yung-Chi Wu

Product Safety Technology Division

Center for Consumer Product Technology

March 1978

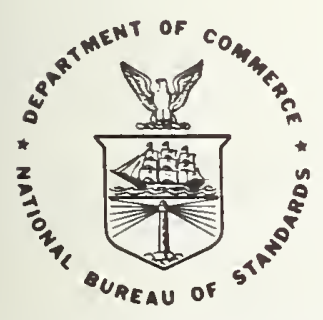

U.S. DEPARTMENT OF COMMERCE NATIONAL BUREAU OF STANDARDS 

NBSIR 78-1452

\section{AN EVALUATION OF CHILDREN'S \\ BITING STRENGTH FOR TOY SAFETY \\ CRITERIA}

Yung-Chi Wu

Product Safety Technology Division

Center for Consumer Product Technology

March 1978

\section{Report To}

Consumer Product Safety Commission

5401 Westbard Avenue

Bethesda, MD 20016

U.S. DEPARTMENT OF COMMERCE, Juanita M. Kreps, Secretary

Dr. Sidney Harman, Under Secretary

Jordan J. Baruch, Assistant Secretary for Science and Technology

NATIONAL BUREAU OF STANDARDS, Ernest Ambler, Director 

siting is a natural function of human beings. Children start to bite when their teeth begin to develop. They use their teeth to cut or incise with the anterior teeth bite size pieces from apples and corn, and to grind with the posterior teeth the bite sized pieces. The more hard foods they eat, the stronger the biting force they develop 1/ and 2/. As they advance in age, their biting activity and their biting force increase. They use their teeth not only for biting and chewing foods, but unfortunately, also as tools with which to manipulate or operate toys and other objects that they encounter.

Children play with toys in imaginative ways. Any toys with hazards induced by "foreseeable and reasonable abuse" are prohibited by law. The hazard of broken toys induced by children's biting falls into such a category. Since children cannot be prevented from biting on toys, biteinduced hazards can be avoided if the stress rupture strength of materials used for toys is greater than the biting strength that children would typically exert on the same materials. In the interest of toy safety it is necessary to find out what the maximum biting strength would be for a given age group of children, so that the minimum compression failure strength of a toy can be predetermined (for example, to accommodate the maximum biting forces exerted by any, or say by $90 \%$, of the population of anticipated users) and the unnecessary hazard of broken toys can be avoided. The pertinent parameters of these relative strengths are discussed.

\section{Bite Induced Fracture of Toys}

All toys are made of materials which have an intrinsic property known as fracture or stress rupture strength. This property is determined by the stress-strain relationship. The rupture stress strength is the stress at which the material fractures (called the fracture point). Elastic materials fracture when the applied stress exceeds the ultimate yield strength of the material $\underline{3 /} \& \underline{4} /$.

The phenomenon of failure by stress rupture is very complicated, particularly for non-elastic materials. Among other factors, they involve the test (or use) conditions, e.g., temperature, time, rate of application of stress and nature of tested material, i.e. brittle or ductile, all of which influence test results. No detail will be given here. However, the applied stress, say the biting force over some constant occlusal area (which is the contact surface of the cusps in the teeth), to induce fracture involves the relative strengths of both teeth and toy. It has been reported that the tooth enamel has an approximate hardness of Brinell No. 285 5/, which corresponds to the hardness of carbon steel with a tensile strength of $9.7 \times 10^{8} \mathrm{~N} / \mathrm{m}^{2}(140,000 \mathrm{psi}) 4 /$. This value of strength is greater than that of most of the materials used for toys, except some metals. High temperature and long periods of loading can cause plastic deformation (creep) and lower the yield strength and fracture point of materials. Since biting action occurs at room or body temperature, the 
effect on the strength of material is negligible. The duration of applied stress, however, may affect the creep of materials 4/. Therefore, the primary concern for the bite induced fracture of toys is the maximum biting force children could exert, the area of occlusion, and the duration of sustaining such force.

\section{Biting Strength and Force}

The biting strength is the biting force acting on the occlusal area of the biting Dlane; the occlusal area is the contact surface of the cusps in the teeth. The number and radii of cusps vary from tooth to tooth. Because of the complexity of the topology of the surface of the teeth, biting forces, instead of biting strengths, are commonly reported in the literature.

The biting force is the total force exerted by the biting muscles which move the lower jaw upwards. In this upward movement, the lower jaw acts like a lever $6 /$. For this reason, the biting force of an individual tooth increases with its position, from anterior to posterior, and reaches a maximum at the first molar $(+6$ or $6+)(+6$ denotes the sixth tooth in the left jaw counted from the first incisor; $6+$ denotes the sixth tooth in the right jaw) $1 /$ \& $7 /$. The biting force on anterior teeth is about one quarter or Iess of the posterior biting force 1/. Apparently, the bite opening that limits the size of an object to be bitten, affects the biting force. The maximum biting force measured is not at the maximum opening of the jaws, and this led to the belief that "there is a critical state of contraction in the muscles of mastication at which the force exerted by them is at its maximum" 8/. For this reason, Worner and Anderson have suggested that, owing to the development of the jaws, the optimum molar bite opening of children increases with age, and is about $10 \mathrm{~mm}$ at age six, and $18 \mathrm{~mm}$ at age ten and older. For children younger than six years, it is of ten less than $7.5 \mathrm{~mm}$, and in the incisal region the optimum bite opening is in the neighborhood of $20 \mathrm{~mm}$ I/.

The level of the biting force, as discussed by Carlsson 1/, is governed by the neuromuscular control mechanism activated by the afferent impulses from the masticatory system. These impulses are balanced in such a way as to give the greatest comfort in biting action. Therefore, a sensation of pressure in the joints, muscles, tendons, periodontal tissues and teeth which indicate that any further increase in biting force may cause pain is one of the important factors limiting the maximum biting force.

The physiological function also limits the duration of sustaining the maximum biting force to 2 to 3 seconds. Heinroth $9 /$ reported that "A measurement lasting 15 seconds was illustrated by $\bar{a}$ diagram (not shown). The curve rises during the first two seconds up to about $30 \mathrm{kgf}(300 \mathrm{~N})$, whereafter the force lessens during the following two seconds down to about $1 \mathrm{kgf}(10 \mathrm{~N})$. This weak condition lasts barely three seconds, whereafter the curve rises in two seconds to a maximum of about $40 \mathrm{kgf}(400 \mathrm{~N})$, only to fall rapidly to zero." Linderholin and Wennstron 10/ have shown that their subjects can produce the maximum biting forces for about 3 seconds. 
It should be noted that the above measurements were performed on adults. Children may have a lower tolerance limit for pain or discomfort (no data available), so that one second for such duration is suggested.

Force is a vector quantity, and biting force, F, as generally determined, is not normal to the biting plane. Therefore, the vertical (normal) component, $F_{n}$, of the biting force, $F$, exerted by teeth will be: 6/ \& 11/

$$
F_{n}=F \cos \theta
$$

where $\theta$ is the angle between the direction of the applied force of occlusion and that normal to the occlusal plane of the tooth. Because of the complex surface topology of the tooth cusps, the angle $\theta$ is difficult to measure and results in a wide range of values. However, its maximum value is estimated to be 20 to 40 degrees $11 /$. The lowest value of $F_{n}$, then, will be greater than $75 \%$ of the biting force measured.

Since the strength of a material is defined in terms of force per unit area, and biting forces are generally reported in force alone, the occlusal area needs to be considered.

The total occlusal area for a given tooth depends on the material being bitten. If it is a hard and brittle material, it will make essentially point contact with the cusps and the contact area is difficult to assess. If the material is not so hard and is deformable under the compression of biting force, the surface contact area may be estimated from the number and curvature radius of cusps of a given tooth. Thus, in mastication, it has been reported that the lower first molar of an adult has an occlusal area of about $50 \mathrm{~mm}^{2}$ 11/. Furthermore, Strenger 12/ has measured the curvature radii of the cusps of the molars and premolars and reported a mean value of $1.07 \mathrm{~mm}$. He also reported the mean number of impressions (the number of cusps of each tooth varies, so that the mean value was taken) on the biting plane by cusps of individual premolar and molar teeth as show in Table 1.

\section{Table 1}

\section{Number of Impressions by Cusps of Individual Tooth}

Tooth Position

$+X$, left; $X_{+}$, right

No. of Impressions

$$
+7 \quad+6
$$$$
+5
$$

$+4 \quad 4+$

$5+$

$6+$

$7+$

53

2

12

2

4 3

Both values for the radii and the number of cusps are statistically significant (over 200 measurements 12/). In assessing the occlusal area, these statistical values are used because the variation of both the number (table 1) and the curvature radii $(0.3 \mathrm{~mm}$ to $2.1 \mathrm{~mm}$ ) is so great; from cusp to cusp in the same tooth, also from tooth to tooth and from person to 
person. The total occlusal area for a given tooth, assuming a semispherical surface of each cusp is estimated as follows:

$$
A=2 \pi r^{2} n
$$

Where $r=$ mean radius of curvature of cusps

$\mathrm{n}=$ number of cusps

Using the values cited above, the estimated maximum occlusal area for a molar tooth would be $\left(52(2 \pi)\left(1.07^{2}\right)=36 \mathrm{~mm}^{2}\right.$. This value agrees reasonably with the value of $50 \mathrm{~mm}^{2}$ given above. It should be noted that this occlusal area was obtained from teeth of adults. Since the deciduous teeth. are smaller, smaller occlusal areas would have been obtained if experiments had been performed on children prior to the erupting of the first permanent molar.

\section{The Biting Force of Children}

The development of human teeth, within broad limits of variability in both order and eruption age, may be summarized in table 2 13/.

\section{Table 2}

\section{Development of Dentition}

Deciduous dentition

Lower central incisors

Upper incisors

Lower lateral incisors and 1st molars

Canines

2nd molars

Permanent dentition

1st molars

Central incisors

Lateral incisors

1st premolars

2nd premolars

Canines

2nd molars

3rd molars
6-9 months

8-10 months

15-21 months

16-20 months

20-24 months

The deciduous teeth number 20, viz., 2 incisors, 1 canine, and 2 molars, on each side of each jaw. These deciduous teeth, 20 in number, begin to be replaced by permanent teeth around the fifth year. It should 
be noted that premolar teeth never erupt in the deciduous dentition. The permanent teeth number 32 when they are fully erupted. They are: 2 incisors, 1 canine, 2 premolars, and 3 molars on each side of each jaw.

The development of biting force follows the development of jaw bones and biting muscles. This general trend, in turn, follows the advancement of age but it may differ from individual to individual. Therefore, in order to determine the biting force, experimental measurements are necessary. The measurement of biting force has been recorded as far back as the 17 th century $1 /, 6 / \& 12 /$ and has continued. There are several review articles $1 /, \sigma / \& 12 / \overline{i n}$ the literature that give evaluations of measurements of biting forces of human subjects ranging from 3 to 30 years of age. Some of the early recorded values are generally assessed as inaccurate because of poor designs of the measuring instrument and inadequate assessments of the biting mechanism. Nevertheless, the relative value of different age groups is of interest; from these the rate of growth of biting force for children may be projected. It is generally observed that the biting force increases with age up until the late teens and then levels off. In particular, Brawley and Sedwick 14/ have reported that biting force increases over $22 \mathrm{~N}$ ( 5 lbf) per year from 6 to 17 years of age.

The maximum biting forces may differ widely among the same age groups for children as well as for adults. Thus, some younger children have shown a strong biting force compared with older children. Some children of kindergarten age have demonstrated biting force values of $400 \mathrm{~N}$ (88 1bf) 1/ , which are almost the same as that of adults. This variation of biting force is apparently due to the state of dentition.

The most influential factors on the biting force, in addition to the eating habits, and the development of jaw bones and muscles, are the health condition of teeth and their surrounding tissues 1/. Thus, Worner and Anderson $7 /$ reported that "the estimated average molar biting forces for the children of all ages in this state (Australia) appear to be much lower than those recorded for American children. It is suggested that this may be attributed to the general lack of dental consciousness in this community and to the fact that a large number of Victorial children are 'lazy eaters'." The authors further stated that "the average biting pressures on the first permanent molars of the girls at the boarding school were above those of the hospital patients, and these results were in turn above those of children at a State school (Australia) in an industrial suburb. . . The lower molar biting strength of the former scholars (state school children) is thought to be due to a lack of dental consciousness and very poor oral health." Krogman 15/ recently has reported the biting forces of children 3 to 6 years of age in Oakland, Calif. and in Philadelphia, Pa. The maximum biting force of American children is comparable to those in Western Europe and is much higher than those in Australia as the Australian authors stated. All of these results are summarized in the accompanying figures.

Figures 1 and 2 show the mean values of the maximum biting forces in the molar regions, which were computed by Worner and Anderson 16/ from earlier investigations. Figure 3 is reproduced from Linke and Dette 17/ for the maximum biting force of the deciduous molars $(+6$ or $6+$ ) of 
individual children. Figure 4 is plotted for the highest values taken from Krogman 15/.

It can be seen from these figures, that the measured values for biting force are highly scattered. There is no available means to evaluate what is the best value for the biting force of a given age group. Because the measuring, techniques varied among all the authors, the results cannot be statistically compared with each other. However, in the interest of child safety, some safety factors are required for the evaluation of the bite induced hazards. It is reasonable to consider the highest values of the biting force of each age group.

Figures 1 and 2 show only mean values which, if chosen as the force for testing the bite resistance of toys, might protect the majority of children but would not protect those whose biting force is higher than average. The values shown in figure 3 are particularly interesting. The data covers not only the age range of interest, but also gives the month of each age group. The highest biting forces of a given age (including month) are replotted in figure 5. As pointed out previously, the biting force increases with age, and assuming that the increase is linear, a straight line is fitted to those highest values as the maximum biting forces for this age group (3-7 years). Although Krogman's highest values as shown in figure 4 are higher than those shown in figure 5, Krogman did not show whether his results were obtained from biting with an opposing single or with two adjacent teeth. In view of his measuring instrument and the instructions that were given to his test subjects, it appears that some of his results could have been the biting force exerted by two adjacent teeth. Therefore, Krogman's highest values are high compared to those with single opposing molar teeth. However, based on Mansour's observations on adults, the biting force of the first molars $(+6$ or $6+)$ is higher than that of the second premolars $(+5$ or $5+$ ) by about $40 \%$ 6/. Assuming the same relative biting strength for children's two deciduous molar teeth, then Krogman's highest values will be reduced $(X / 1.6)$ and would be compatible with those values shown in figure 5 .

It is interesting to note that most values referred to above are measurements of the biting force of the deciduous or the first permanent molars $(+6$ or $6+)$ of children. There appears to be no quantitative data on the biting force of two adjacent deciduous molar teeth reported in the literature. However, it has been observed that the resultant biting force of the two incisor teeth for adults is approximately additive 19/. If the resultant biting force of these two deciduous molar teeth is additive and the relative biting forces are 1:0.6 as observed for adults, the resultant force will be greater by a factor of 1.6 than the maximum biting force of the second deciduous or the first permanent molar $(+6$ or $6+)$. However, the occlusal area of the two teeth together is also approximately 1.6 times that of the second deciduous molar $(+6$ or $6+)$ as estimated from the values in Table 1. In this case, the biting force increases with the occlusal area, but the biting strength of the two adjacent deciduous molars remains approximately the same as that of the second deciduous molar. Thus, this relationship may be approximately formulated as follows: 
where $\quad B=$ biting strength

$F, F^{\prime}=$ biting force of single and adjacent teeth, respectively

$A, A^{\prime}=$ the corresponding occlusal areas of single and adjacent teeth, respectively.

\section{Toy Safety Aspect of Biting Force}

The maximum biting forces reported in the literature, with the possible exception of Krogman's, were measured on the second deciduous or the first permanent molar $(+6,6+)$ of children. Therefore, the occlusal area was estimated for these teeth. It should be noted that the occlusal area as discussed in the preceding section depends on the material being bitten. It may be a point contact for hard and brittle materials and, therefore, no area could be estimated. If the materials used for toys are deformable under the compression of biting force, the estimated occlusal area may be used. There is no data available from which to simulate the actual biting actions of children. Variables include the number and location of teeth that are used, the occlusal area involved, and the size of the mouth opening. However, it has been pointed out in the preceding section that the maximum biting strength of two adjacent deciduous molar teeth is about the same as that of the second deciduous molars. Therefore, the following assessment of the maximum biting force is based on the values for the second deciduous or the first permanent molars.

There appear to be six factors which influence the safety aspect of bite induced toy failure; namely, the optimum molar teeth bite opening, the biting force, the biting angle, the occlusal area, the duration of sustaining the maxinum biting force, and the hardness of the enamel of teeth. The first four factors are related to the biting strength, and the last two factors are pertinent to the ultimate yield strength of materials used in toys that may be subjected to biting actions. Furthermore, the values for the last four factors are taken to be constant for all ages of children, whereas the first two biting factors vary from age to age, and among. the same age group.

Since children have very limited knowledge of what is hazardous, in their play with toys, they require maximum protection. Further, although toys are generally intended for children in a given age group (0-18 months, 18-36 months, and 36-96 months), there can be no assurance that they will be used only by the intended age user, especially if there are older siblings in the home. Therefore, in the interest of protecting children from the hazards of bite-broken toys, the highest biting strength (biting force; area, molar bite opening) of the upper age group in a given age bracket is recommended for the evaluation of the minimal required fracture strength of materials used in toys. 
The bite opening has certain effects on the biting force. However, the optimum opening to yield the maximum biting force of an individual, has been disputed and has not been measured experimentally 1/. Furthermore, Worner et. al. themselves have used a measuring pad of size $(18 \mathrm{~mm})$ which is greater than their suggested optimum opening limits for measurements on children of ages 4 to 18, and their recorded biting forces show no drastic change for the age range due to such openings. It appears that there is insufficient data on the optimum opening to determine the size limit of objects that may be bitten on by children. On the other hand, there is a criterion for "small objects" hazards, which requires a size greater than $32 \mathrm{~mm}\left(1 / 4^{\prime \prime}\right)$ in diameter. For the sake of maximum protection of children, it is suggested that toys and their external parts with size of $32 \mathrm{~mm}$ and smaller should be required to withstand the maximum biting strength of children. The other five factors are evaluated as follows:

\section{Constant Factors}

1. The biting angle - this angle is taken as 30 degrees which is the mean of the highest $\left(33^{\circ}\right)$ and the lowest $\left(22^{\circ}\right)$ values reported.

2. The occlusal area - this area is taken to be $50 \mathrm{~mm}^{2}$.

3. The duration of biting - the duration of sustained maximum biting force is taken to be one second.

4. The hardness of the tooth enamel - this is taken to be approximately Brinell 非85, which is equivalent to the hardness of carbon steel with a tensile strength of 140,000 psi $\left(9.7 \times 10^{n}\right.$ $\left(\mathrm{N} / \mathrm{m}^{2}\right)$.

\section{Biting Force}

The highest maximum biting forces of children frorn age 3 to 7 years are shown in figure 5. There appears to be no value reported in the literature for children younger than three years of age. Above age seven, the reported mean values are show in figures 1 and 2 . To be consistent, the extrapolated values for ages 18 months and 8 years from figure 5 are taken. They are:

$$
\begin{aligned}
& 0-18 \text { months }-177 \mathrm{~N}(40 \mathrm{lbf}) \\
& 18-36 \text { months }-255 \mathrm{~N}(57 \mathrm{lbf}) \\
& 3-8 \text { years }-540 \mathrm{~N}(121 \mathrm{lbf})
\end{aligned}
$$

It should be noted that these biting forces are not the vertical (normal) forces to the biting plane, which are needed for the evaluation of the bite induced hazard. In order to obtain normal forces, equation 1 is used, and a biting angle of 30 degrees is employed. Furthermore, according to Table 2, children at ages of 18 nonths and under do not have their second deciduous molar teeth which exert the highest biting force before the permanent molars are erupted. If the relative biting force of the 
first deciduous molars is taken to be $40 \%$ less than that of the second as discussed previously, and if the occlusal area is assurned to be approximately $20 \%$ less than that taken in the above section, the estimated maximum vertical force for age of 18 months will be:

$$
(177)(1-.4 \%)(\cos 30) /(1-.2 \%)=115 \mathrm{~N}(26 \mathrm{lbf})
$$

Children of ages 36 months and up already have their second deciduous molars whose area is taken to be a constant as $50 \mathrm{~mm}^{2}$. The estimated inaximum vertical forces for these age groups are:

$$
\begin{aligned}
& 18-36 \text { months }(255)(\cos 30)=221 \mathrm{~N}(501 \mathrm{bf}) \\
& 3-8 \text { years }(540)(\cos 30)=468 \mathrm{~N}(1051 \mathrm{bf})
\end{aligned}
$$

\section{Conclusions and Recommendations}

In view of the foregoing discussions and the information presented, it is suggested that the following criteria be considered in evaluating the bite induced hazards of toys.

1. The duration of sustained maximum biting force is 1 second.

2. The upper size limit of toys subject to evaluation is $32 \mathrm{~mm}$ ( 1 1/4") for all ages.

3. The maximum vertical biting forces for different age groups are:

$0-18$ months - $111 \mathrm{~N}(25 \mathrm{lbf})$

18-36 months - 222 N (50 lbf)

\section{3-8 years - $445 \mathrm{~N}(100 \mathrm{lbf})$}

4. The occlusal area is $50 \mathrm{~mm}^{2}$.

It should be noted that the above criteria for force level and occlusal area are based on measurements cited for single molar teeth and that the mean radius of curvature for molar cusps is $1.07 \mathrm{~mm}$. It is suggested that any rational device which is chosen for testing the bite resistance of toys should have a radius of no less than $1 \mathrm{~mm}$ (rounded number) on the test edges. Furthermore, assuming that the occlusal area is the same as the contact surface area, the test force should be chosen in accordance with equation 3, above. 



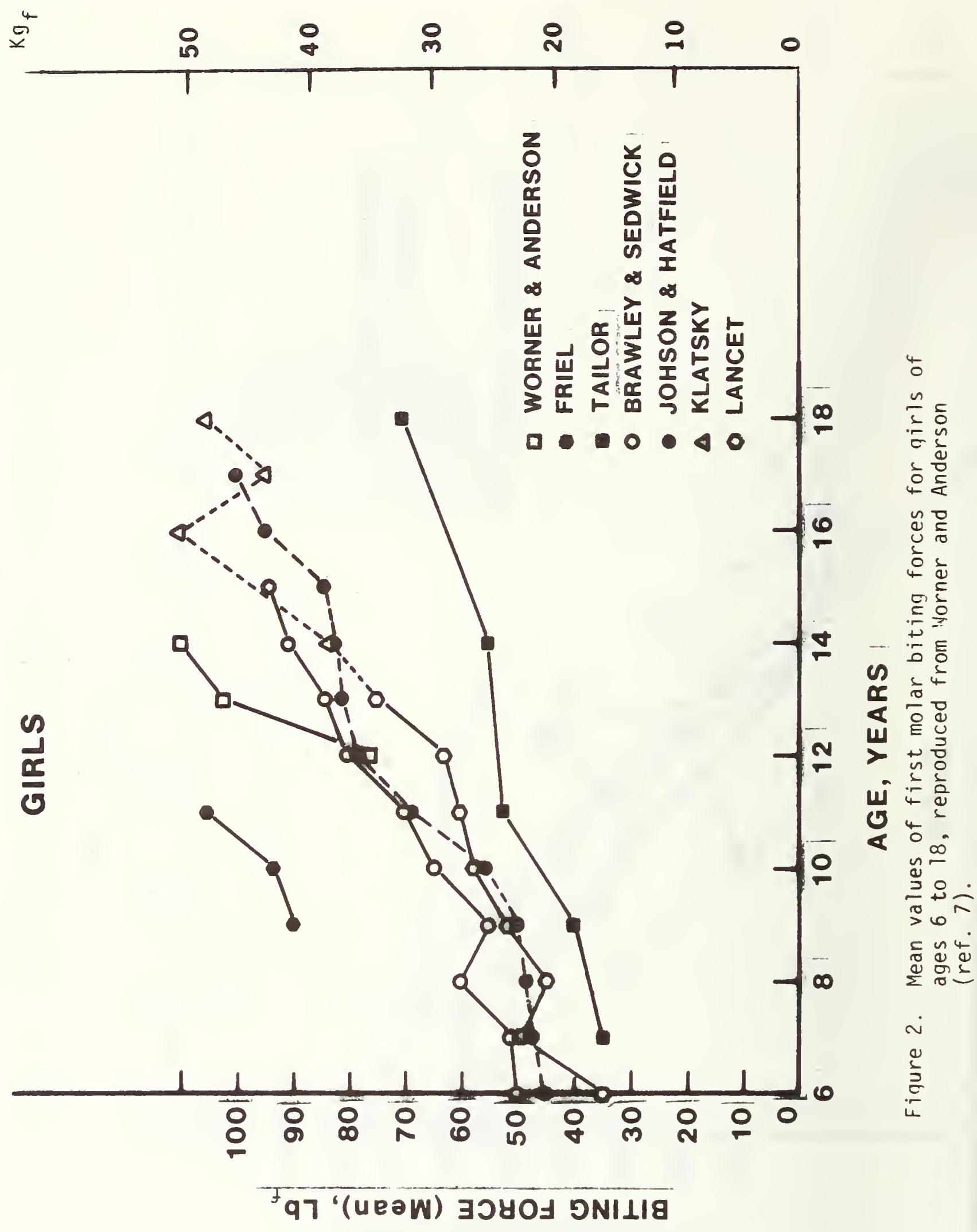




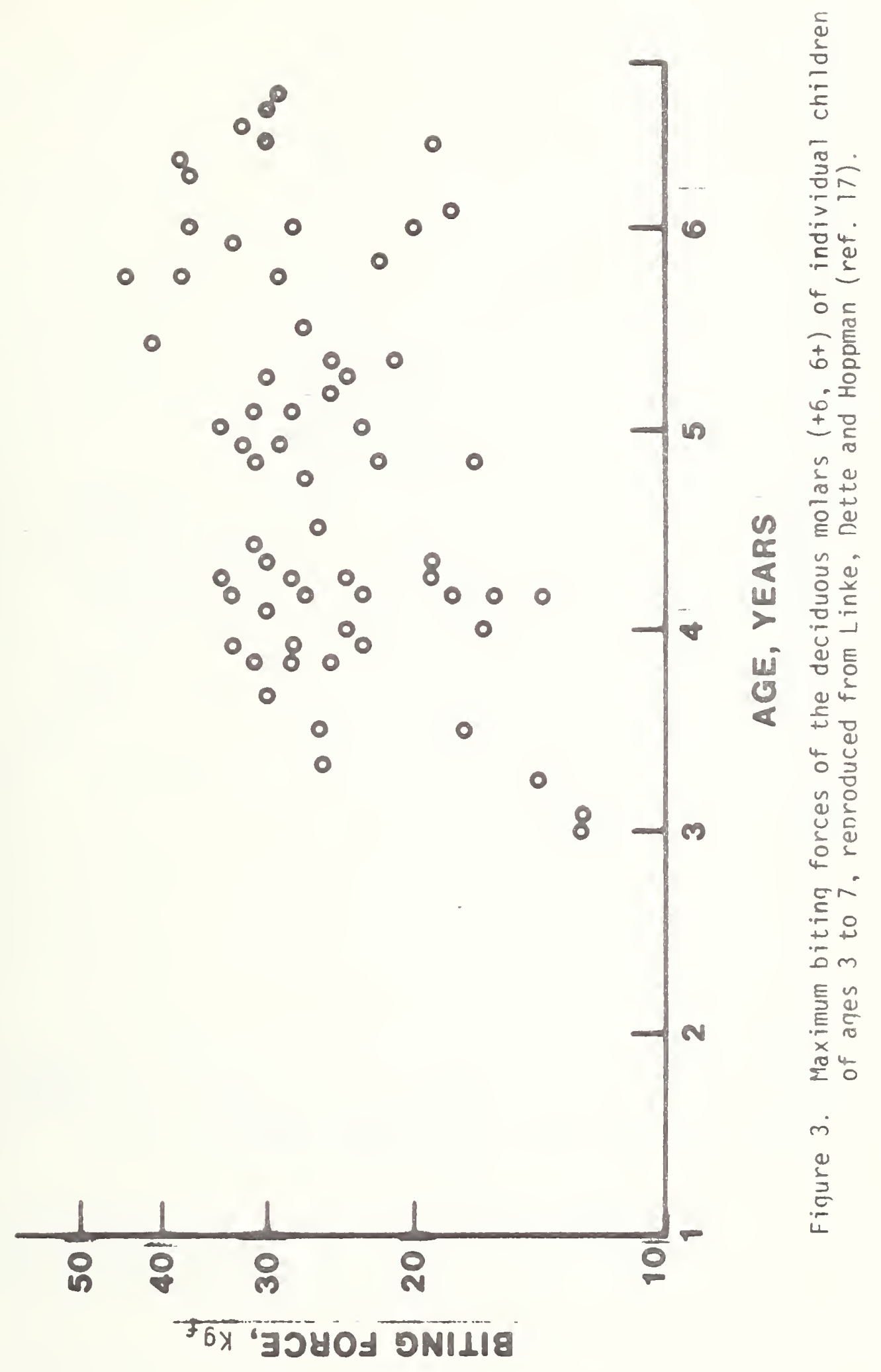




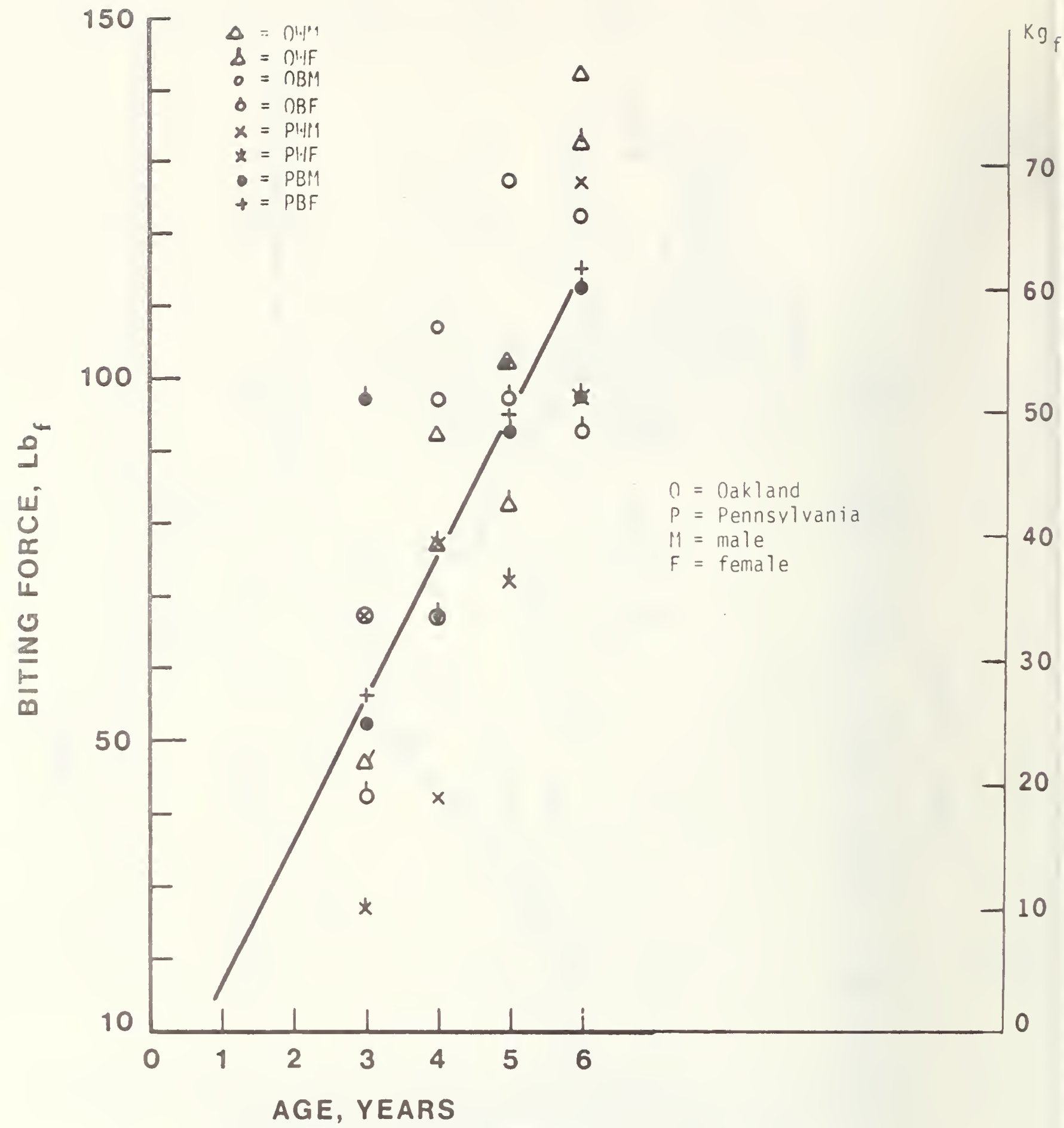

inure 1. Highest hitina forces of children. Data taken from kromman (ref. 15). The solid line indicates the mean values. 


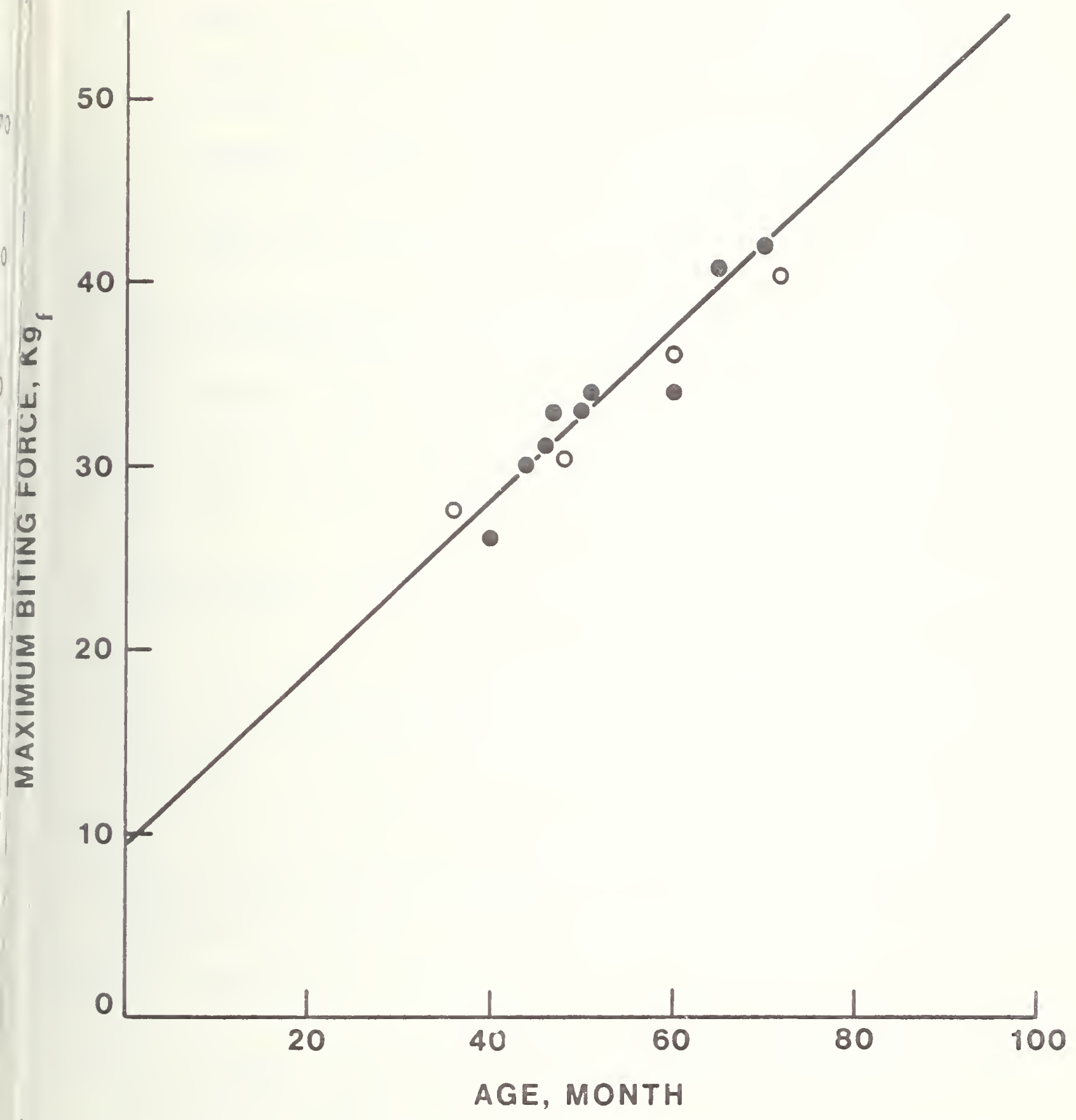

Figure 5. The highest biting forces of a qiven ane taken from fiqure $3(0)$ and finure $4(0$, see text). 

1. E. Carlsson, Front. Oral Physiol., 1, 265 (Krager, Basel 1974).

2. G.N. Jenkins, Physiology of the Mouth, Blackwell Scientific Publications, Oxford, England (1966)

3. S. Timoshenko, Strength of Materials, 3rd Ed., D. Van Nostrand Co., New York, NY (1955).

4. J.H. Faupel, Engineering Design, John Wiley and Sons, Inc., New York, NY (1964)

5. Wilmer Souder and G.C. Paffenbarger, Physical Properties of Dental Materials, NBS Circular No. 433 (1942).

6. R.M. Mansour, Drexel Tech. Jour., 34, 32 (1972).

7. H.K. Worner and M.N. Anderson, Austral. J. Dent. 48, 1 (1944).

8. R.H. Boos, J.A.D.A., 27, 1192 (1940), cited by Worner et. al. (ref. 7).

9. Hans Heinroth, cited by F. Strenger, Biting Force in Man, Stockholm, Siveden (1949).

10. H. Linderholm and A. Wennstrom, Acta Odont. Scand. 28, 679 (1970).

11. R.S. Ledley, Engineering Analysis of Dental Forces, Theory and Application, National Biomedical Research Foundation, Silver Spring, MD (1969).

12. F. Strenger, Biting Force in Man, Stockholm, Sweden (1949).

13. M.F. Ashley Montagu, Anthroplogy: Physical, Methods in Medical Physics, Vol. 2, Ed. O. Glasser, The Year Book Publishers, Inc., Chicago, Ill. (1950).

14. R.E. Brawley and H.J. Sedwick, Int. J. Orthodontia, 24, 256 (1938), cited by Worner, et. al. (ref. 7).

15. W.M. Krogman, "The Manual and Oral Strengths of American White and Negro Children, Ages 3-6 years" A Report to Glass Container Manufacturers Institute, Inc. (1971).

16. Literatures cited by Worner and Anderson, ref. 7 .

17. P.G. Linke, K.E. Dette and I. Hoppmann, Aertzliche Jugenkunde, Leipzig, 62, 338 (1971).

18. K.E. Dette, I. Hoppmann and P.G. Linke, Deutsche Zahn-, Mund-Und Kieferheilkunde, 59, 399 (1972).

19. Yoshihide Maeda, J. Tokyo Dent College Soc. 73, 434 (1973). 

$1.1144(A \in V .7 .73)$

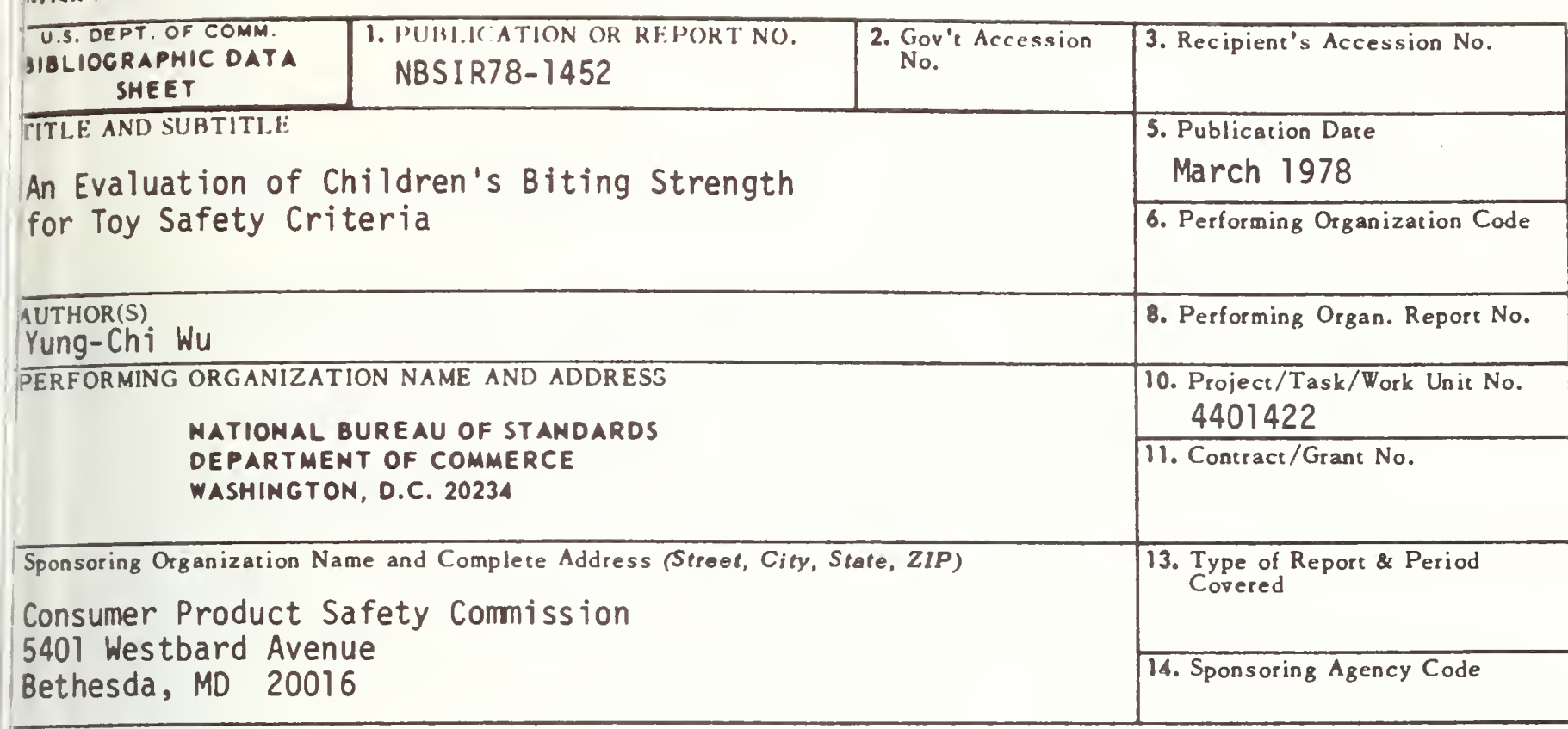

SUPPLEMENTARY NOTES

ABSTRACT (A 200-word or less factual summary of most sienificant infarmation. If document includes a significant bibliography of literature survey, mention it here.)

Children's biting strength (biting force over the occlusal area) is one of the major parameters in evaluating the bite induced broken-toy hazard. The estimation of biting strength includes the assessments of controlling factors that influence the maximum biting force and the occlusal area. Values for biting strength are discussed accordingly. Since only the maximum biting forces (over a constant area of measuring device) of the deciduous molars or the first permanent molars are given in the literature, and since the biting strength of single opposing molars is approximately equal to that of two adjacent opposing molars, the maximum biting forces for single molars are evaluated. In the interest of child safety, the highest biting strength (biting force and area) of upper age group in a given age bracket is recommended. Other parameters, such as molar bite opening, time for sustaining maximum biting force, and the hardness of the enamel of teeth are also discussed.

- KEY WORDS (six to twelve entries; alphabetical order; capitalize only the first letter of the first key word unless a proper name; separated by semicolons)

Bite opening; biting force; biting strength; cusps; dentitions; duration of sustained maximum biting force; hardness of enamel; occlusal area.

\section{AVAILABILITY}

For Official Distribution. Do Not Release to NTIS

XX] Order From Sup. of Doc., U.S. Government Printing Office Washington, D.C. 20402, SD Cat. No.C13

Order From National Technical Information Service (NTIS) Springfield, Virginia 22151

\begin{tabular}{|l|c|}
\hline $\begin{array}{l}\text { 19. SECURITY CLASS } \\
\text { (THIS REPURT) }\end{array}$ & 15 \\
UNCL ASSIFIED & 21. NO. OF PAGES \\
\hline $\begin{array}{l}\text { 20. SECURITY CLASS } \\
\text { (THIS PAGE) }\end{array}$ & 22. Price \\
UNCLASSIFIED & USCOMM-DC 29042-P74
\end{tabular}


